\title{
Toxicity of Endophyte-Infected Tall Fescue Alkaloids and Grass Metabolites on Pratylenchus scribneri
}

\author{
A. A. Bacetty, M. E. Snook, A. E. Glenn, J. P. Noe, N. Hill, A. Culbreath, P. Timper, P. Nagabhyru, and C. W. Bacon \\ First, second, third, and ninth authors: United States Department of Agriculture-Agricultural Research Service (USDA-ARS), Toxicology \\ and Mycotoxin Research Unit, Richard Russell Research Center, Athens, GA; first, fourth, and sixth authors: Department of Plant \\ Pathology, and fifth author: Department of Crop and Soil Science, University of Georgia, Athens; seventh author: USDA-ARS, Crop \\ Protection and Management, Tifton, GA; and eighth author: Department of Plant Pathology, University of Kentucky, Lexington.
}

Accepted for publication 12 August 2009.

\begin{abstract}
Bacetty, A. A., Snook, M. E., Glenn, A. E., Noe, J. P., Hill, N., Culbreath, A., Timper, P., Nagabhyru, P., and Bacon, C. W. 2009. Toxicity of endophyte-infected tall fescue alkaloids and grass metabolites on Pratylenchus scribneri. Phytopathology 99:1336-1345.

Neotyphodium coenophialum, an endophytic fungus associated with tall fescue grass, enhances host fitness and imparts pest resistance. This symbiotum is implicated in the reduction of stresses, including plantparasitic nematodes. To substantiate this implication, toxicological effects of root extracts, polyphenolic fraction, ergot, and loline alkaloids from endophyte-infected tall fescue were investigated using Pratylenchus scribneri, a nematode pest of tall fescue. In vitro bioassays and greenhouse studies were used as tests for effects of root fractions and com-

todes/pot, compared with 4,866 and 8,450 nematodes/pot for noninfected grasses. The in vitro assay indicated that root extracts from infected tall fescues were nematistatic. Polyphenols identified in extracts included chlorogenic acid, 3,5-dicaffeoylquinic acids, caffeic acid, and two unidentified compounds, but these were not correlated with endophyte status, qualitatively or quantitatively. Tests of several ergot alkaloids revealed that ergovaline and $\alpha$-ergocryptine were nematicidal at 5 and $50 \mu \mathrm{g} / \mathrm{ml}$, respectively, while ergocornine and ergonovine were nematistatic at most concentrations. Loline ( $\mathrm{N}$-formylloline), the pyrrolizidine alkaloid tested, was nematicidal (50 to $200 \mu \mathrm{g} / \mathrm{ml}$ ). The ecological benefits of the metabolites tested here should assist in defining their role in deterring this nematode species while offering some probable mechanisms of action against plant-parasitic nematodes in general.
\end{abstract} pounds on motility and mortality of this lesion nematode. Greenhouse studies revealed that endophyte-infected tall fescue grasses are essentially nonhosts to $P$. scribneri, with root populations averaging 3 to 17 nema-
Additional keywords: Festuca arundinacea, fungal endophyte, Lolium arundinaceum, pyrrolizidine alkaloids.
Tall fescue (Festuca arundinacea, synonyms Lolium arundinaceum $=$ Schedonorus arundinaceus $)$ is the predominant perennial, cool-season turf and forage grass species in the United States that covers over 20 million ha of pastureland. After the 1977 discovery of the endophyte status as a cause of animal toxicity (2) and the demonstration that the association of tall fescue infected with Neotyphodium coenophialum (Morgan-Jones \& W. Gams) Glenn, C. W. Bacon, \& Hanlin and its toxic ergot alkaloids (23) resulted in a defensive mutualism $(8,37)$, there have been several experiments to examine the interaction strategies of each symbiont. The fungal symbiont produces nonconidiating, symptomless intercellular infections of tissue of the leaf sheaths, inflorescence stems, and seed of tall fescue. The root and leaf blade are not infected. This biotrophic clavicipitalean fungus is the hybrid anamorphic state of several Epichloe spp. that can produce diseases in other grasses and sedges. In tall fescue, the infection is entirely symptomless and the fungal symbiont is seed disseminated.

Symbiotic tall fescue is tolerant to numerous abiotic and biotic stresses and diseases, which is attributed to the interactive nature of this endophytic fungus. Of particular importance is the report of resistance to nematodes. The lesion nematode, Pratylenchus scribneri, is commonly associated with forage grasses and has been shown to reproduce on tall fescue $(5,19)$. P. scribneri is an

Corresponding author: C. W. Bacon; E-mail address: charles.bacon@ars.usda.gov

doi:10.1094/PHYTO-99-12-1336

This article is in the public domain and not copyrightable. It may be freely reprinted with customary crediting of the source. The American Phytopathological Society, 2009. obligate parasite that feeds and migrates in the cortical tissue of plant roots $(5,36)$. This and other species continuously travel within their host's roots, feeding and moving from cell to cell $(5,22,35)$. P scribneri can also travel freely in the rhizosphere, moving in and out of the root, and the resulting damage and necrosis can result in secondary invasion of other soilborne pathogens, and has been shown to reproduce on tall fescue $(5,19,22)$. Research has suggested that endophyte presence in tall fescue is associated with reduced numbers of various plantparasitic nematodes in the soil and on grass roots (12). West et al. (40) and Kimmons et al. (19) compared population densities of $P$. scribneri in the roots and soil surrounding tall fescue plants with and without the endophyte. They found fewer nematodes in the endophyte-infected grass roots than in endophyte-free roots, and fewer nematodes were in the surrounding soil of endophyteinfected grass than in endophyte-free grass. This population reduction supports previous findings that endophyte-infected tall fescue may be resistant or tolerant to several species of nematodes (33).

The mechanisms responsible for the above tolerance to nematode infection remain uncertain. In a recent study, Panaccione et al. (31) used gene knock-out technology to determine the effects the ergot alkaloids, ergovaline, agroclavine, and setoclavine on $P$. scribneri in perennial ryegrass (L. perenne) infected with a hybrid Neotyphodium endophyte. The results showed that ergovaline caused a significant reduction in nematode numbers, and that nematode reduction followed the infection status of the grass. However, Panaccione et al. (31) concluded that ergot alkaloids were not responsible for nematode toxicity. Because ergot alkaloids are not produced significantly in perennial ryegrass as 
opposed to tall fescue, any nematode resistance might totally reside in the plant component of the association for L. perenne. Further, nematode infection or natural resistance is not a documented problem in perennial ryegrass. In addition to ergot alkaloids, tall fescue contains several other alkaloids that are toxic to several natural pests and livestock $(6,21,37)$. Moreover, plant products have been implicated in various pest antagonisms (20). For example, an increased amount of phenolic compounds, a class noted for its toxicity to nematodes $(10,25,30,36,41-43)$, has been documented in roots of tall fescue (26). Further, alterations in root morphology and cell surface chemistry, reflective of an altered translocation flow for at least the phenolics, are also associated with $N$. coenophialum-infected tall fescue (26). Therefore, phenolic compounds of tall fescue are suggested as being interactive in nematode toxicity.

The sensitivity of nematodes to the presence of the endophytic fungus may be the result of one or more of the inhibitory alkaloid compounds, such as the ergot alkaloids. Inhibitory compounds may be important in reducing the populations of some nematodes by affecting their feeding habits, survival, or reproductive rates (16). Despite these and other studies, doubt remains because there is still a question of whether the Neotyphodium endophyte causes the reduction in the densities of soil nematodes (10), probably due to the lack of associating identifiable ergot alkaloids, and other toxins from the fungus or increased plant polyphenolics resulting from the symbiotum. Thus, the involvement of the endophyte in protecting tall fescue from nematode parasitism, while highly suggestive, is still in early investigative stages. The objectives of this research were to determine whether various alkaloids identified previously as being toxic to other animals are also toxic to $P$. scribneri and, because there is some debate over the total involvement of these fungal alkaloids as nematotoxins, we also examined any roles played by the major tall fescue phenolics, a class of compounds that has been implicated as having compounds capable of expressing nematotoxicity. Toxicity of these compounds and fractions were undertaken with the use of an in vitro bioassay using $P$. scribneri, a major nematode species in tall fescue $(5,22)$.

\section{MATERIALS AND METHODS}

Nematode preparation. The original sterile culture of P. scribneri was generously provided by Dr. Susan Meyer (Beltsville, $\mathrm{MD})$. The nematodes were cultured on corn root explants using the following procedure. Maize kernels (Zea mays L.) of hybrid Pioneer 3223 were surface disinfected for $10 \mathrm{~min}$ in $100 \%$ bleach (5.25\% sodium hypochlorite) followed by a 15 -min soak in $95 \%$ ethanol. Nine to ten surface-sterilized seeds were placed onto $1.5 \%$ water agar (15 g/liter) (Difco Laboratories, Detroit) plates and allowed to incubate in the dark at $25^{\circ} \mathrm{C}$ for 3 to 5 days. Primary roots were cut and transferred to Gamborg's B5 agar (Gibco, Carlsbad, CA) to which agar at $15 \mathrm{~g} /$ liter was added, $\mathrm{pH}$ 5.7 (35). Plugs from the original Meyer plates were transferred onto the fresh sterile roots as needed. Inoculum of $P$. scribneri was prepared from the culture plates by washing the surface of the B5 medium with sterile, distilled water $\left(\approx 25^{\circ} \mathrm{C}\right)$, and the nematode solution was transferred to sterile conical tubes for a stock solution. The concentration of nematodes in this stock solution was adjusted with sterile distilled water according to each experiment.

Nematode inoculation in soil. The sandy loan (a Cecil soil type) used in this work was pretreated twice by steam heating for $3 \mathrm{~h}$. Subsamples of the soil were placed in sterile distilled water overnight and observed with a stereoscope for any signs of nematodes and insects. The soil was placed in 1020.3 -cm-diameter azalea pots and planted with five Neotyphodium spp.-infected or noninfected ramets of the tall fescue cv. Jesup. Each pot was sampled to microscopically screen for the presence or absence of endophyte hyphae in the outermost leaf sheath (15). Once the endophyte status was confirmed, the pots were separated based upon whether or not they were to be inoculated with nematodes. Three pots of grasses of each endophyte status were inoculated with 1,500 nematodes in $10 \mathrm{ml}$ of water. Two holes, $1 \mathrm{~cm}$ in diameter by $2 \mathrm{~cm}$ deep, were bored in the soil at opposite sides of a potted plant, and $5 \mathrm{ml}$ of the nematode inoculum (150 nematodes $/ \mathrm{ml}$ ) was pipetted into each hole. The holes were covered with more steam-sterilized sandy soil and the plants were watered. The pots were randomly arranged in the greenhouse, watered as needed to maintain soil moisture, and fertilized as above. Experiments were repeated for statistical analysis.

Assessment of nematode numbers in soil. Measurements of nematode numbers in the soil of pots were performed at 30,45, and 60 days post-nematode inoculation. The 30- and 45-day measurement periods were performed as follows: a $100-\mathrm{cm}^{3}$ soil sample was taken from each of the three replicate pots using a core borer. These three soil cores were combined and holes were backfilled with sterile sandy loam soil and watered. Total plant root damage was not assessed until the final 60-day sampling period so that the entire plant could be harvested. The final 60 -day measurement was performed by removing $\approx 900 \mathrm{~cm}^{3}$ of soil from each pot using a core borer. Root wet weights were determined on core or total pot contents, depending on the analysis, by washing the soil from the roots through a $200-\mu \mathrm{m}$ sieves, transferring the roots to tarred blotting paper, and gently drying the roots with additional blotting paper, and weights were determined.

The centrifugal flotation technique was used to extract nematodes from soil (18). A $100-\mathrm{cm}^{3}$ subsample of soil from each pot was suspended in $500 \mathrm{ml}$ of sterile distilled water, vigorously stirred for $20 \mathrm{~s}$, and allowed to settle for $1 \mathrm{~min}$. The soil slurry was poured onto 40 - and $400-\mu \mathrm{m}$ nested sieves. Nematodes were then washed into a $150-\mathrm{ml}$ beaker and poured into $50-\mathrm{ml}$ centrifuge tubes. The tubes were centrifuged at $420 \times g$ for $5 \mathrm{~min}$ and the supernatant was carefully decanted off the nematode pellet. The pellet was replaced with an equal volume of the sucrose solution ( $454 \mathrm{~g}$ of sucrose liter ${ }^{-1}$ of $\mathrm{H}_{2} \mathrm{O}$ ), mixed, and centrifuged for $60 \mathrm{~s}$ at $420 \times g$, where the sugar-nematode suspension was then decanted onto a 400- $\mu$ m mesh sieve. The nematodes were rinsed from the sieve with a wash bottle containing sterile distilled water into a 50-ml beaker, and the volume adjusted to $15 \mathrm{ml}$. This solution was mixed, and $1 \mathrm{ml}$ was placed into a counting dish for counts using a stereomicroscope. Counts were repeated three times on separate 1-ml aliquots and averaged.

Nematode assessment in tall fescue roots. Nematode concentrations inside tall fescue roots were determined on $500-\mathrm{cm}^{3}$ of root and soil from each of the three replicate pot of the 30- and 45-day treatment groups using a core borer. This nematode soil material was run through an elutriator, and the roots were evenly distributed into small paper-lined azalea pots. A misting chamber was set up with clean glass funnels, with plastic tubing attached to the ends clamped at the lower 5 to $7.6 \mathrm{~cm}$ of the tubing. Cold water was poured into the funnels to a level just below the small pots. The pots were placed on top of the funnels and the misting chamber door shut. The pots were water misted at a 1-min interval for $30 \mathrm{~s}$ over a 48 -h period, which allows the lesion nematodes to escape the roots and flow with the water into the plastic tubing attached to the ends of the funnels and settle to the lower 5 to $7.6 \mathrm{~cm}$ of the tubing. After $48 \mathrm{~h}$, the clamp was released to allow the lower $20 \mathrm{ml}$ to be captured into $50-\mathrm{ml}$ beakers. Counts of a 1-ml subsample of each beaker were performed in counting dishes under a stereomicroscope. Nematode numbers in the roots at the final 60-day time period were extracted in a similar fashion but on a larger scale. After the final soil sampling, the entire root system was submerged into water to release any remaining soil. The roots were then removed with scissors and lightly rinsed to remove debris. The roots from each pot were thoroughly mixed, 
weighed, and placed onto the mist chamber as described above. However, because there was more root material placed into the mist chamber pots, the mist chamber was allowed to run for 5 days $(120 \mathrm{~h})$ instead of the standard $48 \mathrm{~h}$. Nematode counting was completed at 48,72 , and $120 \mathrm{~h}$ as described above.

Assay for nematode toxicity. An in vitro toxicity bioassay was developed to compare the effects of the various compounds produced in $N$. coenophialum-infected $F$. arundinacea and noninfected $F$. arundinacea on nematode motility under sterile conditions. This bioassay was a modification of Meyer et al. (29) that has been demonstrated as an effective toxicity bioassay to nematodes from several mycotoxins and fungal extracts $(7,30)$. Purified compounds as well as total root extracts and methanolic fractions of endophyte-infected and noninfected tall fescue cv. Jesup and the clonal Kentucky 31were filter sterilized and tested against mixed stages of $P$. scribneri.

All assays were conducted in a Fisher Scientific Isotemp incubator at $26^{\circ} \mathrm{C}$ in sterile 12 -well flat-bottomed polystyrene tissue culture plates (Corning Costar) previously scratched with 2-mm gridlines on the bottom for ease of nematode counting. Nematode inocula were prepared from culture plates as described above. In total, $1 \mathrm{ml}$ of the lesion nematodes $(\approx 140$ to 150 nematodes $/ \mathrm{ml})$ was pipetted into each well of the tissue culture plates, followed by $1 \mathrm{ml}$ of either the filter-sterilized test compounds or water controls. Plates were allowed to sit undisturbed at room temperature in the dark for the duration of an experiment.

Nematode motility was evaluated at 24,48 , and $72 \mathrm{~h}$ after addition of the test solution. Nematodes were observed under a $\times 10$ objective of a dissecting scope and those that did not immediately appear to be motile were gently probed with a dissecting needle to initiate movement. If, after probing, the nematodes remained motionless, they were deemed nonmotile, following the procedure of Meyer et al (29). Following the final time period, all liquid was removed by pipette and replaced with fresh, room-temperature, sterile distilled water. Nematodes were allowed to sit in the fresh water at room temperature for an additional 24 to $96 \mathrm{~h}$, where motility observations were repeated as previously described. Nematodes that did not immediately appear motile were gently probed with a dissecting needle to initiate movement. If, after probing, the nematodes remained motionless, they were considered dead.

Analysis of root extracts for nematotoxicity. Two cultivars of tall fescue were used. Seed-sown endophyte-infected or noninfected tall fescue cv. Jesup was used for most experiments. In experiments designed to determine the accumulation of polyphenols over a 3-month collection period, clones of endophyteinfected and noninfected tall fescue were produced from an individual clump of infected Kentucky 31 tall fescue by using a propiconazole procedure (3). All plants were grown in $10.6-\mathrm{cm}-$ diameter pots in either a synthetic soil mix (Fafard Professional Mix) or the sandy loam. The plants were maintained under routine greenhouse conditions, with regular watering and fertilizations as needed. Twenty 2 -week-old tall fescue seedlings of cv. Jesup (10 infected and 19 noninfected with $N$. coenophialum) were transplanted to 20.3 -cm-diameter plastic azalea pots filled with the sterilized synthetic soil mix. The pots were randomly arranged in the greenhouse, watered 4 days per week to maintain soil moisture, and fertilized with Osmocote's Slow Release Plant Food, 19-6-12 (Marysville, OH). Six weeks post transplanting, each pot was repotted into 26.5 -liter pots that would allow for extensive root growth for the entire length of the experiment (August 2003 to May 2004). Plants from both groups were screened for confirmation of endophyte infection or absence by microscopic examination of the outermost leaf sheath (14).

Twelve randomly selected 22-week-old plants of Jesup endophyte-infected and noninfected tall fescue were harvested and gently rinsed to remove soil. Roots (45 g wet weight) were ground in $500 \mathrm{ml}$ of methanol using a Polytron tissue grinder and filtered (Whatman no. 2), and the methanol was evaporated to dryness under vacuum using a rotoevaporator at $45^{\circ} \mathrm{C}$. The residues were weighed and a stock solution prepared by dissolving the residue in sterile distilled water that was filter sterilized (Acrodisc Syringe Filter, $0.2 \mu \mathrm{m}$, HT Tuffryn Membrane). The stock solutions were adjusted with sterile distilled water to yield final root extract concentrations of 115, 287.5, $862.5,1,150,1,725$, and $2,400 \mu \mathrm{g} / \mathrm{ml}$. The in vitro bioassay was conducted as previously described using $\approx 130$ nematodes/well. Experiments were repeated four times using fresh plant residue batches, and differences between endophyte-infected and noninfected extracts were determined with a $t$ test $(P=0.05)$.

Extraction and quantitation of polyphenols. Analysis of roots from the Kentucky 31 clone for total polyphenol contents were performed on $\approx 1.0 \mathrm{~g}$ of washed roots, which was placed in 20 -ml scintillation vials (with teflon cap liners), and $15 \mathrm{ml}$ of methanol was added. Prior to analysis, $1 \mathrm{ml}$ of a methanolic chrysin solution (chrysin recrystallized from amyl alcohol; $0.06 \mathrm{mg} / \mathrm{ml}$ ) was added as an internal standard. After grinding the roots with the polytron, the solutions were filtered through a $0.45-\mu$ m nylon membrane filter and aliquots analyzed by reversed-phase high-performance liquid chromatography (HPLC) using an $\mathrm{H}_{2} \mathrm{O} / \mathrm{MeOH}$ linear gradient of 10 to $100 \% \mathrm{MeOH}$ in $35 \mathrm{~min}$, a flow of $1 \mathrm{ml} / \mathrm{min}$, and detection at $340 \mathrm{~nm}$. Each solvent contained $0.1 \% \mathrm{H}_{3} \mathrm{PO}_{4}$. HPLC analyses were performed with a Beckman Ultrasphere $\mathrm{C}_{18}, 5-\mu \mathrm{m}$ column (4.6 by $250 \mathrm{~mm}$ ) (Beckman Instruments, Norcross, GA) using a HewlettPackard 1050 diode array HPLC. Quantitation was performed using chlorogenic acid's response factor for all compounds.

Preparative reversed-phase separation of polyphenols for bioassay analysis. The $1,150-\mu \mathrm{g} / \mathrm{ml}$ water extract from the total root extract experiment was separated by preparative reversed-phase chromatography following our earlier procedure (14). This extract was placed on $\approx 5 \mathrm{~g}$ of Waters BondaPak $\mathrm{C}_{18}$ bulk packing material (Millipore Corp., Milford, MA), packed into a glass chromatography column ( $1.25 \mathrm{~cm}$ i.d. by $15 \mathrm{~cm}$, LabCrest chromatography column; nitrogen pressure at 15 psi used to aid flow) (Andrews Glass Co., Vineland, NJ), washed with $\mathrm{MeOH}$, and recycled to $\mathrm{H}_{2} \mathrm{O}$. The root extract was applied to the column, and fractions sequentially eluted with $60 \mathrm{ml}$ of water followed by $40 \mathrm{ml}$ each of a 10, 20, 40, 60, and $80 \% \mathrm{MeOH} / \mathrm{H}_{2} \mathrm{O}$ solution, and finally $100 \% \mathrm{MeOH}$. The phosphoric acid was omitted from these solvents. All fractions were evaporated to dryness and the required amount of water added to each fraction to equal the original root weight of $1,150 \mu \mathrm{g} / \mathrm{ml}$.

Identification of polyphenols. Chlorogenic acid and the 3,5dicaffeoylquinic acid (3,5-DICQA) were identified by comparison with the retention times of standards (14). These identifications were confirmed using HPLC-mass spectrometry (MS) to ascertain the molecular masses (354 for chlorogenic acid and 516 for 3,5DICQA) and to match the fragmentation patterns with that of the standards.

A Finnegan LCQ Duo with ESI was used to obtain the mass spectra for the analyses. The system was equipped with a SpectraSystem P2000 HPLC pump, a SpectraSystem AS3000 auto injector, and a SpectraSystem UV6000LP UV/Vis detector, monitoring $340 \mathrm{~nm}$, for tandem UV-MS analyses. With the instrument in negative ion mode, the mass spectrometer parameters were tuned on the $343(\mathrm{M}-\mathrm{H})$ ion obtained by direct injection of the chlorogenic acid standard (Sigma Aldrich, St. Louis).

For the chromatographic analyses, a Beckman Coulter Ultrasphere ODS column, 4.6 by $250 \mathrm{~mm}-5 \mu \mathrm{m}$ of packing, was used to provide separations. The solvent system used was methanolwater, with $1 \%$ formic acid added; linear gradient began at $10 \%$ methanol and increased to $100 \%$ over 50 min, then was held at $100 \%$ methanol for another $10 \mathrm{~min}$. For HPLC analyses, Xcalibur, the system control software, was run in data-dependent mode, isolating and fragmenting the most intense ion (by collisional ion dissociation [CID], 45\%) found in each scan.

The in vitro bioassays of the chemical fractions were conducted as previously described using $\approx 130$ lesion nematodes/well. Con- 
trols consisted of methanol and water treatments. Experiments were repeated four times with fractions prepared from fresh root extracts, and differences between fractions were determined with a $t$ test $(P=0.05)$.

Bioassay of specific toxins for nematicidal activity. All ergot alkaloids were obtained from Sigma-Aldrich, with the exception of ergovaline that was synthetically prepared (Department of Chemistry, Auburn University). The loline alkaloid was prepared from seed of endophyte-infected tall fescue, which was formylated with ethylformate and purified by silica gel chromatography that resulted in $94 \%$ pure $\mathrm{N}$-formylloline.

Three independent experiments were conducted to determine the individual toxicity of each ergot and loline alkaloid to $P$. scribneri. Toxicity assays were conducted in sterile tissue culture plates as described above. A 1-ml suspension of nematodes (30 nematodes $/ \mathrm{ml}$ ) was pipetted into each well and allowed to sit for $24 \mathrm{~h}$ to allow for recovery from any manipulation shock. Stock solutions were prepared for each alkaloid (ergonovine, ergocornine, $\alpha$-ergocryptine, and loline) and each was diluted to test 5, 50,100 , and $250 \mu \mathrm{g} / \mathrm{ml}$. Each concentration was repeated four times. On day $0,1 \mathrm{ml}$ of a compound was added to their assigned nematode wells, where the plates were allowed to sit undisturbed at room temperature for the duration of the experiment. Nematode motility was conducted as previously described and evaluated at $24,48,72$, and $96 \mathrm{~h}$ after the solution was added.

The effects of the ergot and loline alkaloids were also tested on $P$. scribneri using alkaloid mixtures at various concentrations. Lesion nematodes in $1 \mathrm{ml}$ of water ( 30 nematodes $/ \mathrm{ml}$ ) were pipetted into wells and allowed the $24-\mathrm{h}$ recovery period. Stock solutions of test compounds were prepared for each mixture, consisting of loline + ergocornine $+\alpha$-ergocryptine, loline + ergocornine, loline + $\alpha$-ergocryptine, or ergocornine $+\alpha$-ergocryptine, and each mixture was diluted such that each alkaloid in a mixture produced a total alkaloid concentration of 5, 50, 100, and $250 \mu \mathrm{g} / \mathrm{ml}$. Each dilution of a mixture was replicated four times. Nematode motility assays were conducted as previously described and evaluated at 24, 48, 72, and $96 \mathrm{~h}$ after the solution was added. Three independent experiments were performed for statistical analysis.

Statistical analyses. Bioassay data were analyzed using regression analyses (SAS version 9.1) to determine significant differences between root extracts and fractions of endophyteinfected or noninfected fescue and their effects on P. scribneri. Regression testing (SAS version 9.1) was also used to determine significant differences of data generated from in vitro bioassays testing the effects of alkaloids, alone and in combination, on
P. scribneri motility. All nematode toxicity data were analyzed as whole-number counts. Duncan's test was used when comparing nematode populations in the roots and soils from each cultivar of endophyte-infected and noninfected tall fescue.

\section{RESULTS}

Soil suppression of $\boldsymbol{P}$. scribneri populations by infected tall fescue. A greenhouse culture study was used to determine whether $N$. coenophialum-infected tall fescue can suppress $P$. scribneri populations in pots. There were significant differences $(P=0.05)$ between the wet root weights from infected and noninfected plants. The wet weights of roots at 30 days postnematode inoculations were 7 and $4 \mathrm{~g} / 100 \mathrm{~cm}^{3}$ for the endophyteinfected and noninfected plants, respectively. At 45 days, the root wet weights for the endophyte-infected and noninfected plants totaled 9 and $5 \mathrm{~g} / 100 \mathrm{~cm}^{3}$, respectively. At the final harvest at 60 days and on a per-pot basis, the average root wet weights for the endophyte-infected and noninfected plants were 97 and $58 \mathrm{~g} / \mathrm{pot}$, respectively.

The 30-day average numbers of nematodes for both the endophyte-infected and noninfected roots were identical with 93 nematodes/pot sample (Table 1). Significant differences in nematode numbers occurred at 45 - and 60-day sampling periods. The entire yield of roots for each pot revealed that nematode numbers were severely depressed in the endophyte-infected plants whereas the noninfected plants were highly infested. Nematode numbers in the soil containing noninfected plants were six times higher than that in the soils from endophyte-infected soil at the 30-day sampling period (Table 2). At day 45, the number of nematodes was 113 to 132 nematodes in the endophyte-infected soils whereas, in the noninfected soils, the average number of nematodes was 350 . At day 60 , the population of nematodes in endophyte-infected soils was 49 to 85 nematodes/pot, whereas the noninfected soils yielded 467 to 750 nematodes/pot.

Root toxicity and chemical analysis of toxic fractions. In order to identify polyphenols and their toxicity to P. scribneri, a comparative toxicity profile of $N$. coenophialum-infected and noninfected roots was made from several concentrations of total root extracts from infected and noninfected plants (Fig. 1A and B). The dilutions ranged from 115 to $2,400 \mu \mathrm{g} / \mathrm{ml}$, which indicated that, after $72 \mathrm{~h}$, significant toxicity was observed from the dilution series prepared from the infected roots (Fig. 1B).

The objective was to assess whether a relationship exists between endophyte status, the concentration of root extracts, and

TABLE 1. Numbers of Pratylenchus scribneri in Festuca arundinacea roots ${ }^{\mathrm{x}}$

\begin{tabular}{|c|c|c|c|c|c|}
\hline \multirow[b]{2}{*}{ Endophyte status } & \multicolumn{5}{|c|}{ Nematode population root counts ${ }^{y}$} \\
\hline & Day 0 & Day 30 & Day 45 & Day 60 & Final $\mathrm{Rf}^{\mathrm{z}}$ \\
\hline Endophyte-infected & 1,500 & $93 \mathrm{a}$ & $43 \mathrm{a}$ & $1 \mathrm{a}$ & 0 \\
\hline Endophyte-free & 1,500 & $93 \mathrm{a}$ & $276 \mathrm{a}$ & $1,734 \mathrm{~b}$ & 1 \\
\hline
\end{tabular}

${ }^{x}$ Nematodes $(\approx 1,500)$ were inoculated into soil of a genetic clone of endophyte-infected and endophyte-free tall fescue cv. Jesup.

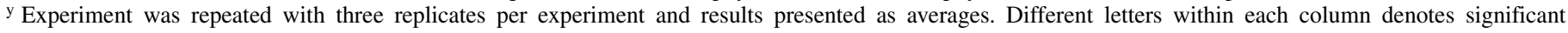
differences according to Duncan's multiple range test $(P>0.05)$.

${ }^{\mathrm{z}}$ Nematode reproductive index $(\mathrm{Rf})=$ final number of nematodes/initial number inoculated on day 0 .

TABLE 2. Numbers of Pratylenchus scribneri in Festuca arundinacea soil ${ }^{\mathrm{x}}$

\begin{tabular}{|c|c|c|c|c|c|}
\hline \multirow[b]{2}{*}{ Endophyte status } & \multicolumn{5}{|c|}{ Nematode population soil counts ${ }^{y}$} \\
\hline & Day 0 & Day 30 & Day 4 & Day 60 & Final $\mathrm{Rf}^{\prime}$ \\
\hline Endophyte-infected & 1,500 & $67 \mathrm{a}$ & $123 \mathrm{a}$ & $75 \mathrm{a}$ & 0.05 \\
\hline Endophyte-free & 1,500 & $433 \mathrm{~b}$ & $350 \mathrm{~b}$ & $600 \mathrm{~b}$ & 0.4 \\
\hline
\end{tabular}

${ }^{\mathrm{x}}$ Nematodes $(\approx 1,500)$ were inoculated into soil of endophyte-infected and endophyte-free grass cv. Jesup.

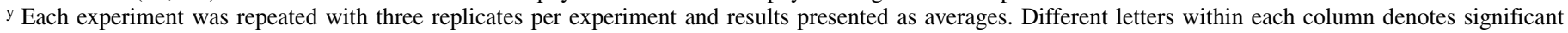
differences according to Duncan's multiple range test $(P>0.05)$.

z Nematode reproductive index $(\mathrm{Rf})=$ final number of nematodes/number inoculated. 
decreased nematode toxicity. The results from the bioassay system indicated that increased concentrations of the extracts from endophyte-infected tall fescue are indeed potentially toxic to $P$. scribneri, as indicated by decreased nematode motility assayed at the 72-h period (Fig. 1). However, it is important to note that, following $72 \mathrm{~h}$ of submersion of nematodes in endophyte-infected extracts, a fresh water replacement step was included to detect reclamation of nematode motility. After a 24-h-period in fresh water, nematode motility was significantly similar to those observed at the 24-h-treatment group (data not shown), suggesting that action of the responsible agent present in the roots was nematistatic.

Results from the previous extract experiment revealed that, at the $1,150-\mu \mathrm{g} / \mathrm{ml}$ concentration, there were relatively few changes in the number of motile nematodes compared with the higher concentrations, indicating an optimum concentration. Therefore, a fractionation study was conducted at this concentration. This data revealed that methanolic root extracts from $N$. coenophialuminfected tall fescue exhibited adverse effects on $P$. scribneri motility (Fig. 2). Motility was not recovered upon endophyte-infected fraction removal and subsequent addition of fresh water, following an extended observation period (data not shown). However, there was no sign of an adverse effect on nematode motility when this concentration was subjected to the methanolic extractions and tested against fractions prepared from noninfected total root extracts (data not shown).

The methanol-soluble polyphenolic compounds from the total root extracts from both types of tall fescues were subjected to HPLC analysis for retention time correlation with standards, acid hydrolysis studies, and HPLC-MS analysis. Four major peaks, A to $\mathrm{D}$, were observed in the HPLC analysis of the initial root extract (Fig. 3). Peaks A and B eluted in the $10 \% \mathrm{MeOH} / \mathrm{H}_{2} \mathrm{O}$ fractions and peak $\mathrm{C}$ eluted in the $20 \%$ fractions whereas peak D, along with two unidentified peaks, $\mathrm{E}$ and $\mathrm{F}$ (not shown), eluted in the $30 \%$ fractions from infected and noninfected Jesup tall fescue. HPLC-MS analysis determined the identity of three of the four major peaks observed in these fractions. Peak A was identified as chlorogenic acid by comparison with an authentic sample (Sigma-Aldrich, Milwaukee,
WI) by HPLC with a retention time and UV spectra correlation, and an HPLC-MS (M/Z $353 \mathrm{M}-\mathrm{H}$, negative ion mode) identical to the standard. Peak D co-eluted with 3,5-DICQA that was isolated and identified from sweet potato as the standard, and acid hydrolysis $\left(0.1 \mathrm{~N} \mathrm{HCl}\right.$ at $100^{\circ} \mathrm{C}$ for 1 to $\left.2 \mathrm{~h}\right)$ produced three chlorogenic acid isomers (3-O-CQA, 4-O-CQA, and 5-O-CQA), caffeic acid, and quinic acid, which were confirmed by HPLC (caffeic acid) and gas chromatography-MS (quinic acid as the silyated derivative). Peak C is an unknown with MW = 548 and HPLC-MS = $547(\mathrm{M}-\mathrm{H}), 385$ (M-162 suggestive of a loss of glucose or caffeic acid), 353 (M-194 possibly chlorogenic acid ion), 223 (M-162-162), and 191 (possible quinic acid ion). This compound has 194 amu higher than compound A, suggesting that it is a methoxylated derivative of chlorogenic acid. Peak D is also unknown and has an MW of 696, and its HPLC-MS has essentially the same spectra as peak A with an added amu of 162, indicating an extra caffeoyl or glucosyl group. The other two minor peaks that are not identified are peak D, MW = 534 and HPLC-MS = $533(\mathrm{M}-\mathrm{H}), 370(\mathrm{M}-162$ possible loss of glucose or caffeic acid), 353 (M-180 possibly chlorogenic acid ion), 209 (M-162-162), and 191 (possible quinic acid ion); in peak D, MW = 534 and HPLC-MS is essentially the same spectrum as peak A.

HPLC analyses were used to measure the amounts of polyphenolics observed in Figure 3. Chlorogenic acid in roots of endophyte-infected and noninfected fescue was found in concentrations of 558 and $339 \mu \mathrm{g} / \mathrm{ml}$, respectively. The caffeoylquinic acid isomer (peak B) in endophyte-infected and noninfected fescue roots were found at concentrations of 118 and $281 \mu \mathrm{g} / \mathrm{ml}$, respectively, while the other unidentified caffeoylquinic acid isomer (peak C) was present at 191 and $813 \mu \mathrm{g} / \mathrm{ml}$, respectively. The last polyphenolic acid, 3,5-DICQA (peak D), was present at 285 and $200 \mu \mathrm{g} / \mathrm{ml}$ in endophyte-infected and noninfected roots, respectively. In addition to the identified polyphenolics, both endophyte-infected and noninfected tall fescue extracts contained several other metabolites (Fig. 3) that may have activity responsible for the decreased nematode activity observed in Figure 1.

Endophyte-infected and noninfected root extracts from the Kentucky 31 tall fescue clone also revealed chlorogenic acid, 3,5-

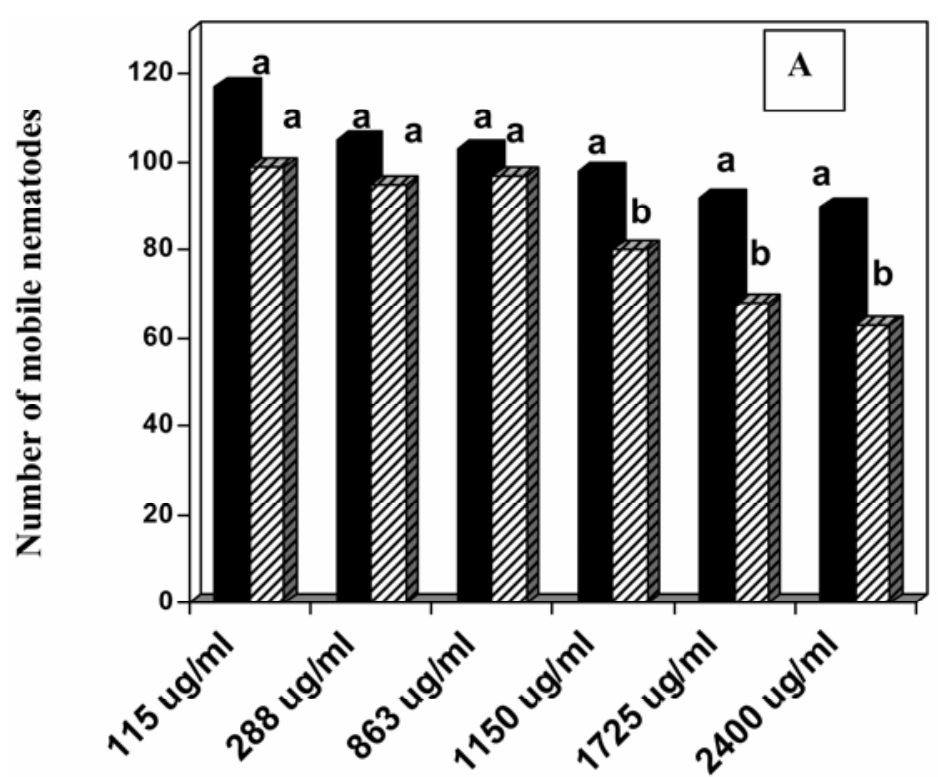

Not infected $\mathbb{Z}$ Infected

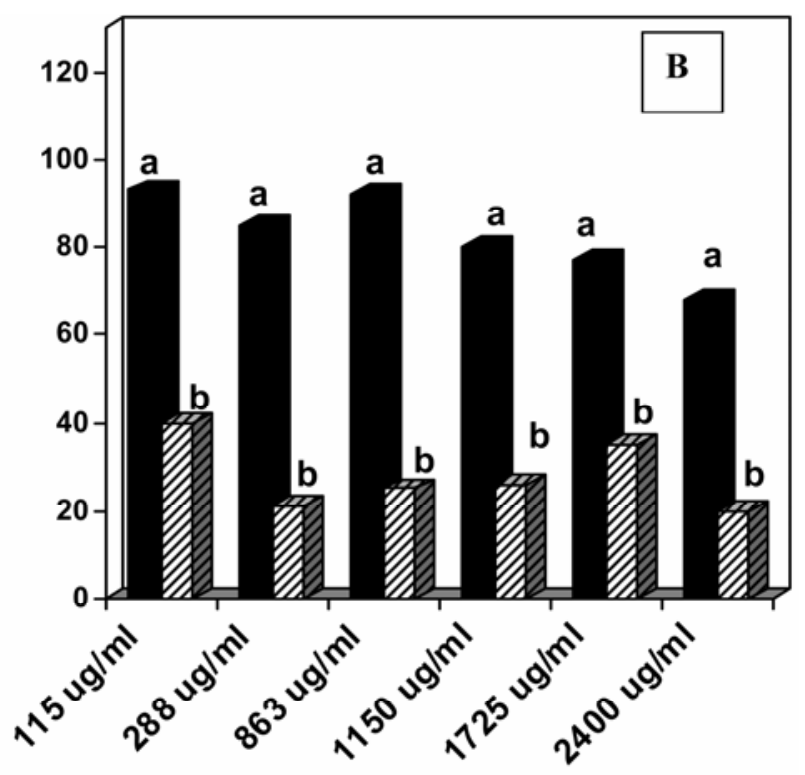

Not infected $\mathbb{Q}$ Infected

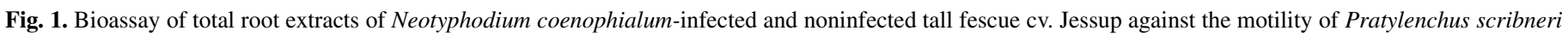

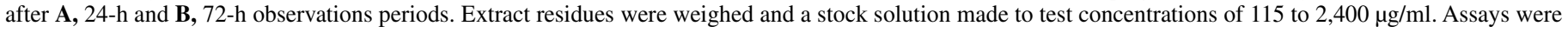

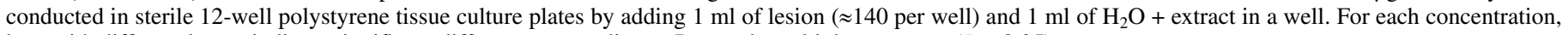
bars with different letters indicate significant differences according to Duncan's multiple range test $(P>0.05)$. 
DICQA, and unidentified peak B (Table 3). Further, roots from endophyte-infected and noninfected fescue roots examined from the clonal line of tall fescue contained the same caffeoylquinic acid-derived polyphenolics but at concentrations that also varied over a 3-month collection period (data not shown). However, the unknown peak $\mathrm{C}$ identified in grasses from cv. Jesup (Fig. 3) was not present in the roots of the Kentucky 31 tall fescue clone. Again, there were no obvious qualitative differences in the major peaks between endophyte-infected and noninfected tall fescue in this clonal line that displayed marked symptoms to infection from P. scribneri (data not shown).

Ergot and loline alkaloid toxicity. The ergot and loline alkaloids were individually tested for toxicity to P. scribneri. At the lowest concentration, $5 \mu \mathrm{g} / \mathrm{ml}$, ergovaline treatments negatively affected nematode with $100 \%$ reduction of motility after $72 \mathrm{~h}$ (Table 4). At the 72-h time period, $100 \%$ of nematode motility ceased in the loline and $\alpha$-ergocryptine treatments in excess of $50 \mu \mathrm{g} / \mathrm{ml}$. Motility in nematodes exposed to ergonovine was severely decreased from the lowest, $5 \mu \mathrm{g} / \mathrm{ml}$, to the highest, $250 \mu \mathrm{g} / \mathrm{ml}$. Ergocornine treatments caused a significant decrease in nematode motility but complete cessation of motility was not observed even at the highest concentration of $250 \mu \mathrm{g} / \mathrm{ml}$. Nematode motility did not recover following removal of ergovaline even after an extended observation period of $96 \mathrm{~h}$ of exposure to fresh water (data not shown). However, nematodes recovered after incubation in water following ergonovine treatments (5 to $100 \mu \mathrm{g} / \mathrm{ml}$ ), ergocornine (all concentrations), and loline (5 to $50 \mu \mathrm{g} / \mathrm{ml}$ ) (data not shown).

Potentiating or synergistic effects of the previously tested alkaloids on nematotoxicity of $P$. scribneri were determined (Table 5). Loline $+\alpha$-ergocryptine mix had an average of 1.0 motile nematode at both $25-$ and $50-\mu \mathrm{g} / \mathrm{ml}$ concentrations that resembled the results of loline when used alone at the $72-\mathrm{h}$ period (Table 4). After $72 \mathrm{~h}$, the mixture of loline + ergocornine and ergocornine $+\alpha$-ergocryptine mixtures had an average of 1.0 motile nematode. After $72 \mathrm{~h}$, the loline + ergocornine $+\alpha$-ergocryptine mix had no motile nematodes across all concentrations. The alkaloid mixtures were removed and nematodes subjected to a fresh water bath for 24 to $96 \mathrm{~h}$, where motility was not recovered in any of the treatments.

\section{DISCUSSION}

Plant-parasitic nematodes have the potential to hamper the establishment and productivity of tall fescue, and may affect plant forage quality $(5,17,23,32,38)$. McGlohon et al. (27) identified 10 genera of nematodes in soil samples from 217 forage crops, and several pasture grasses were identified that were highly suscep-
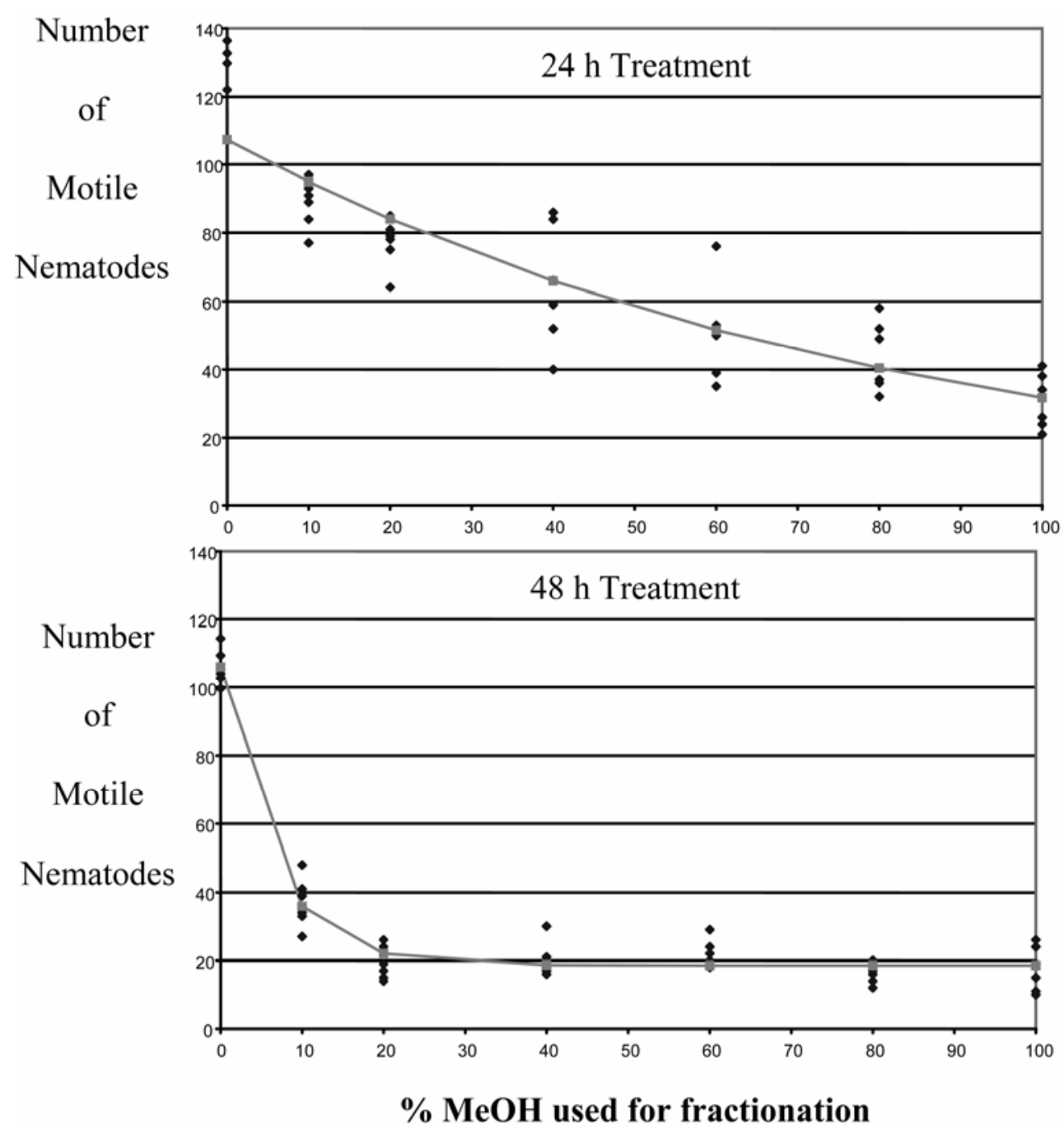

Fig. 2. Bioassay of methanolic fractions of Neotyphodium coenophialum-infected Festuca arundinacea cv. Jesup total root extracts effects on Pratylenchus scribneri. The endophyte-infected total root extracts $(1,150 \mu \mathrm{g} / \mathrm{ml})$ from the previous experiment were poured onto a $\mathrm{C}_{18}$ column and $0,10,20,40,60,80$, and $100 \% \mathrm{MeOH}$ fractions were collected. $\mathrm{MeOH}$ was evaporated and sterile water added to adjust fractions to $\approx 1,150 \mu \mathrm{g} / \mathrm{ml}$. Nematode ( $\approx 140$ per well) motility observations recorded at 24- and 48-h exposure periods. Four independent experiments were performed and differences between fractions are significant at $P<$ 0.05 with a regression fit. 
tible to nematodes (e.g., Kentucky bluegrass). The in vitro assay system revealed that methanolic extracts, fractions, and secondary metabolites from $N$. coenophialum-infected tall fescue exhibited adverse effects on $P$. scribneri activity whereas endophyte-free extracts showed negligible signs of affecting nematode activity. Here, a negative relationship exists between the polyphenols and nematode activity. As concentrations and exposure times to polyphenols increased, nematode motility significantly decreased. However, when subjected to a fresh-water bath, motility was recovered similar to that at the $24-\mathrm{h}$ treatments. Individual com- parison studies of the polyphenols could not be performed because purified forms of each were not obtained from the extracts and only chlorogenic acid was commercially available. Inhibition of motility was reversible in $20 \%$ of P. scribneri during in vitro studies involving chlorogenic acid across all concentrations (10 to $1,000 \mu \mathrm{g} / \mathrm{ml}$ ) (data not shown). The observed induction of nematode paralysis is in agreement with a previous study of Wuyts et al. (42), which documented several phenolics as nematistatic agents.

Grass root exudates contain hydrophobic and hydrophilic substances released into the soils by intact roots. Included in these
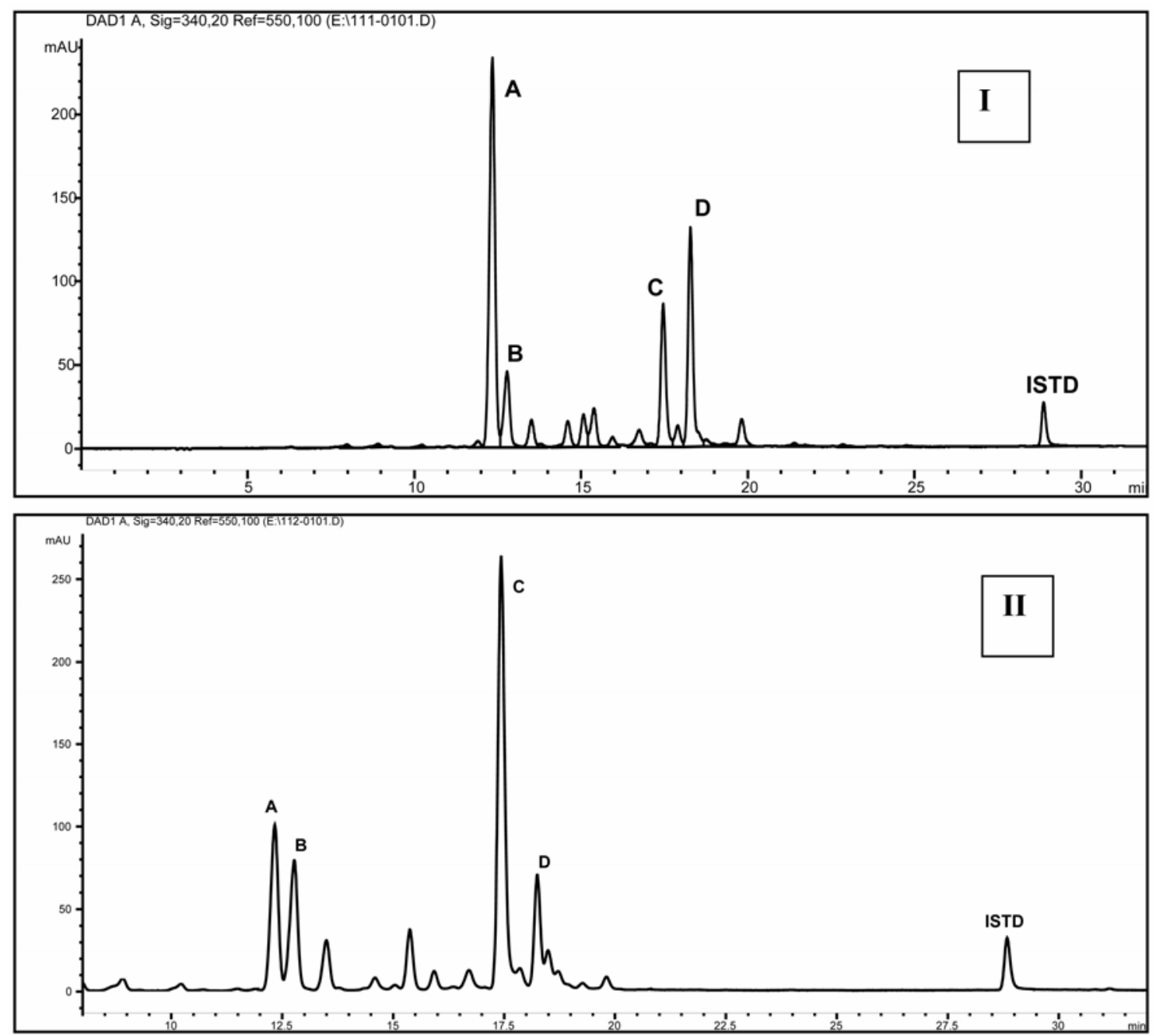

Fig. 3. High-performance liquid chromatogram of methanolic root extracts of endophyte-infected (I) and noninfected (II) tall fescue cv. Jesup. Peak A, Chlorogenic acid; peaks B and C, unidentified caffeoylquinic acid compounds; peak D, 3,5-dicaffeoylquinic acid; ISTD, chrysin, the internal standard.

TABLE 3. Polyphenol content in root tissue of a Neotyphodium-infected (+) and noninfected (-) clonal line of Festuca arundinacea, Kentucky 31, as determined by HPLC analysis over three collecting dates

\begin{tabular}{|c|c|c|c|c|}
\hline \multirow[b]{2}{*}{ Polyphenols } & \multirow[b]{2}{*}{ Endophyte status } & \multicolumn{3}{|c|}{ Content $(\mu \mathrm{g} / \mathrm{g} \text { fresh root weight })^{\mathrm{z}}$} \\
\hline & & January & February & March \\
\hline \multirow[t]{2}{*}{ Chlorogenic acid } & + & $171 \mathrm{a}$ & $1,093 \mathrm{a}$ & $343 \mathrm{a}$ \\
\hline & - & $957 \mathrm{~b}$ & $2,205 \mathrm{~b}$ & $518 \mathrm{~b}$ \\
\hline 3,5-Dicaffeoylquinic acid & - & $509 \mathrm{~b}$ & $504 \mathrm{a}$ & $91 \mathrm{a}$ \\
\hline \multirow[t]{2}{*}{ Unidentified compound B } & + & $61 \mathrm{a}$ & $405 \mathrm{a}$ & $120 \mathrm{a}$ \\
\hline & - & $486 \mathrm{~b}$ & $834 \mathrm{~b}$ & $91 \mathrm{a}$ \\
\hline Caffeic acid & - & $3 b$ & $10 \mathrm{a}$ & $16 \mathrm{a}$ \\
\hline
\end{tabular}

\footnotetext{
${ }^{\mathrm{z}}$ Means of two analyses for each collection month are presented. Different letters within each column denotes significant differences according to Duncan's
} multiple range test $(P>0.05)$. 
substances are various classes of compounds such as organic acids, peptides, amino acids, sugars, and other miscellaneous compounds $(20,26,28)$. Our preliminary data on these fractions prepared from infected and noninfected tall fescue indicated neither quantitative nor qualitative differences (data not reported). However, Malinowski et al. (26) determined that, under a deficiency of phosphorus, there was an even greater increase in total phenolic concentrations in infected tall fescue. The roots of tall fescue grasses are noted producers of exudates that are speculated to be stimulatory, inhibitory, or inactive to organisms (9). Creek and Wade (9) were the first to establish the excretion of phenolic compounds from the root of hydroponically grown tall fescue but Malinowski et al. (26) provided the first evidence that the presence of the endophyte in grass provided for an enhanced amount of phenolic compounds in roots that formed the basis for the approach used in this study.

Soil populations of $P$. scribneri are apparently affected by fescue's endophyte status. Tall fescue infected with the endophyte was essentially free of infection by $P$. scribneri. This outcome is in agreement with the findings of Timper et al. (38), Gwinn and Bernard (11), and Kimmons et al. (19), where there were lower populations of $P$. scribneri in endophyte-infected fescue roots $(1,19,33)$. The mechanisms through which this is accomplished may occur from the presence of natural tall fescue metabolites, fungal endophyte metabolites, or both.

Phenolic compounds belong to one class of natural products that have been associated with resistance in plants against nematodes. Giebel (10) noted a relationship between phenols and nematode resistance in tomato. High phenolic content of some Solanaceae plants are positive indicators of resistance to Heterodera rostochiensis (10). Studies by Plowright et al. (34) suggested that chlorogenic acid has a functional role in the resistance of rice to the stem nematode Ditylenchus angustus and affects nematode coordination. Increases in the content of phenolic compounds in plants challenged by plant-parasitic nematodes have led researchers to draw conclusions regarding their effects on the soil dwelling pest. Anti-nematode activity has also been reported when studying plant extracts of members in the family Poaceae and its effect on Bursaphelenchus xylophilus (pine wood nematode) activity (24). Wuyts et al. (42) determined that polyphenolics were not toxic to $P$. penetrans juveniles but did inhibit egg hatch, presumably by its diffusion into the egg causing paralysis of the developing juvenile. Baldridge et al. (4) detected higher constitutive levels of polyphenols, caffeic and chlorogenic acid in particular, in alfalfa plants resistant to $P$. penetrans, suggesting that caffeic and chlorogenic acids are possible compounds of interest in the control of plant-parasitic nematodes.

The polyphenols identified in tall fescue roots are all structurally related, and the presence of these polyphenols might relate to the chemical instability or enzymatic conversions of each parent compound. For example, chlorogenic acid is readily hydrolyzed to quinic acid and caffeic acid, accounting for the minor amounts of caffeic acid extracted from the roots. Esterification of chlorogenic acid with caffeic acid results in the accumulation of the 3,5-DICQA. The unidentified compounds B and C (Fig. 3; Table 3) are probably related to chlorogenic acid based on molecular weights but they are not the other two isomers of chlorogenic acid (data not reported).

The results from our study are in line with earlier studies $(25,42)$, in that $P$. scribneri motility was inhibited by chlorogenic acid and the constitutive levels of chlorogenic acids were higher in roots of plants that contained few lesion nematode numbers. However, each identified and unidentified polyphenolic acid was higher in noninfected tall fescue than in infected tall fescue although, for some, the differences were not significant. The polyphenolic spectrum observed in the root extracts may not be attributed to the five suspect polyphenolic compounds, because additional phenolic not identified may also exist. Further, some of these polyphenolics are not as toxic to this species of nematode (25). Thus, polyphenols, if they are toxic, are just a piece of the nematode resistance puzzle.

The results from our bioassay examining the affects from individual as well as combinations of specific alkaloids indicated both nematicidal and nematistatic activities. By far the most toxic ergot alkaloid is ergovaline, which is the predominant ergot alkaloid produced by $N$. coenophialum. At concentrations $>50 \mu \mathrm{g} / \mathrm{ml}$,

TABLE 4. Motility bioassay of Pratylenchus scribneri following exposure to serial dilutions of ergot and loline alkaloids

\begin{tabular}{|c|c|c|c|c|c|c|c|c|}
\hline \multirow[b]{3}{*}{ Alkaloid treatments } & \multicolumn{8}{|c|}{ Nematode motility per concentration $(\mu \mathrm{g} / \mathrm{ml})$ at each time period $(\mathrm{h})^{\mathrm{z}}$} \\
\hline & \multicolumn{2}{|c|}{$5 \mu \mathrm{g} / \mathrm{ml}$} & \multicolumn{2}{|c|}{$50 \mu \mathrm{g} / \mathrm{ml}$} & \multicolumn{2}{|c|}{$100 \mu \mathrm{g} / \mathrm{ml}$} & \multicolumn{2}{|c|}{$250 \mu \mathrm{g} / \mathrm{ml}$} \\
\hline & $24 \mathrm{~h}$ & $72 \mathrm{~h}$ & $24 \mathrm{~h}$ & $72 \mathrm{~h}$ & $24 \mathrm{~h}$ & $72 \mathrm{~h}$ & $24 \mathrm{~h}$ & $72 \mathrm{~h}$ \\
\hline Control & $29 \mathrm{a}$ & $29 a$ & $29 \mathrm{a}$ & $29 a$ & $29 \mathrm{a}$ & $29 a$ & $29 a$ & $29 \mathrm{a}$ \\
\hline Loline (NFL) & $8 c$ & $3 \mathrm{~d}$ & $4 d$ & $0 \mathrm{~d}$ & $0 \mathrm{~d}$ & $0 \mathrm{~d}$ & $0 \mathrm{~d}$ & $0 \mathrm{c}$ \\
\hline Ergonovine & $5 \mathrm{~d}$ & $5 \mathrm{c}$ & $4 c$ & $2 \mathrm{c}$ & $3 \mathrm{c}$ & $1 \mathrm{c}$ & $1 \mathrm{c}$ & $0 \mathrm{c}$ \\
\hline Ergocornine & $13 \mathrm{~b}$ & $9 \mathrm{~b}$ & $13 \mathrm{~b}$ & $8 \mathrm{~b}$ & $13 \mathrm{~b}$ & $6 \mathrm{~b}$ & $12 \mathrm{~b}$ & $4 \mathrm{~b}$ \\
\hline$\alpha$-Ergocryptine & $9 \mathrm{c}$ & $3 \mathrm{~d}$ & $4 c$ & $2 \mathrm{c}$ & $0 \mathrm{~d}$ & $0 \mathrm{~d}$ & $0 \mathrm{~d}$ & $0 \mathrm{c}$ \\
\hline Ergovaline & $1 \mathrm{e}$ & $0 \mathrm{e}$ & $0 \mathrm{e}$ & $0 \mathrm{~d}$ & $0 \mathrm{~d}$ & $0 \mathrm{~d}$ & $0 \mathrm{~d}$ & $0 \mathrm{c}$ \\
\hline
\end{tabular}

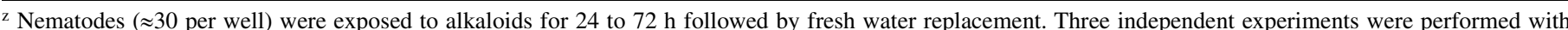
four replicates and results presented as averages. Different letters within each column denotes significant differences according to Duncan's multiple range test $(P>0.05)$. Using a regression fit test, when compared with controls, differences between alkaloids were significant at $P<0.05$.

TABLE 5. Motility bioassay of Pratylenchus scribneri following exposure to ergot and loline alkaloid combinations

\begin{tabular}{|c|c|c|c|c|c|c|c|c|}
\hline \multirow[b]{3}{*}{ Alkaloid combinations } & \multicolumn{8}{|c|}{ Nematode motility per concentration $(\mu \mathrm{g} / \mathrm{ml})$ at each time period $(\mathrm{h})^{\mathrm{z}}$} \\
\hline & \multicolumn{2}{|c|}{$5 \mu \mathrm{g} / \mathrm{ml}$} & \multicolumn{2}{|c|}{$50 \mu \mathrm{g} / \mathrm{ml}$} & \multicolumn{2}{|c|}{$100 \mu \mathrm{g} / \mathrm{ml}$} & \multicolumn{2}{|c|}{$250 \mu \mathrm{g} / \mathrm{ml}$} \\
\hline & $24 \mathrm{~h}$ & $72 \mathrm{~h}$ & $24 \mathrm{~h}$ & $72 \mathrm{~h}$ & $24 \mathrm{~h}$ & $72 \mathrm{~h}$ & $24 \mathrm{~h}$ & $72 \mathrm{~h}$ \\
\hline Control & $21 \mathrm{a}$ & $21 \mathrm{a}$ & $21 \mathrm{a}$ & $21 \mathrm{a}$ & $21 \mathrm{a}$ & $21 \mathrm{a}$ & $21 \mathrm{a}$ & $21 \mathrm{a}$ \\
\hline Loline + ergocornine & $4 \mathrm{c}$ & $1 \mathrm{c}$ & $1 \mathrm{c}$ & $0 \mathrm{c}$ & $1 \mathrm{~b}$ & $0 \mathrm{~b}$ & $0 \mathrm{~b}$ & $0 \mathrm{~b}$ \\
\hline Loline $+\alpha$-ergocryptine & $6 \mathrm{~b}$ & $1 \mathrm{~b}$ & $0 \mathrm{c}$ & $1 \mathrm{~b}$ & $0 \mathrm{c}$ & $0 \mathrm{~b}$ & $0 \mathrm{~b}$ & $0 \mathrm{~b}$ \\
\hline Ergocornine $+\alpha$-ergocryptine & $7 \mathrm{~b}$ & $1 \mathrm{c}$ & $4 \mathrm{~b}$ & $0 \mathrm{c}$ & $1 \mathrm{~b}$ & $0 \mathrm{~b}$ & $0 \mathrm{~b}$ & $0 \mathrm{~b}$ \\
\hline Loline + ergocornine $+\alpha$-ergocryptine & $3 \mathrm{c}$ & $0 \mathrm{c}$ & $0 \mathrm{c}$ & $0 \mathrm{c}$ & $0 \mathrm{c}$ & $0 \mathrm{~b}$ & $0 \mathrm{~b}$ & $0 \mathrm{~b}$ \\
\hline
\end{tabular}

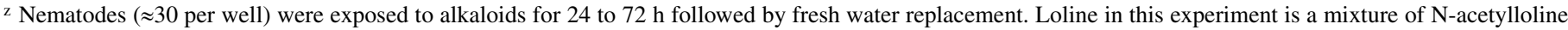
and $\mathrm{N}$-formylloline. Three independent experiments were performed with four replicates and results presented as averages. Using a regression fit test, when compared with controls, the differences between alkaloid combinations were significant at $P<0.05$. 
nematotoxicity is associated with individual ergopeptide, lysergic acid amide, and the pyrrolizidine alkaloids. However, from the data presented here, there appears to be a potentiating nematicidal effect on $P$. scribneri when they are exposed to a combination of ergopeptides (ergocornine and $\alpha$-ergocryptine) and the loline alkaloids at low concentrations of $10 \mu \mathrm{g} / \mathrm{ml}$. These alkaloids do occur in endophyte-infected tall fescue as mixtures, albeit at concentrations that are lower in the roots than in the canopy (37); therefore, it is realistic to conclude that the phenomenon exhibited in this study is not a laboratory-induced artifact but is actually a common occurrence in the environment whereby plant-parasitic nematodes may be strongly affected in one or more stages of their life cycle.

We did not attempt to measure ergot or loline alkaloid concentrations in the roots of endophyte-infected tall fescue but other researchers have examined the content of roots. Bush et al. (6) reported root concentrations of NFL in tall fescue of 274 to $290 \mu \mathrm{g} / \mathrm{g}$ of root, which are in range with the concentrations tested in this study. Panaccione et al. (31) found ergot alkaloids at concentrations of 0.04 to $0.06 \mu \mathrm{g} / \mathrm{g}$ and these plants exhibited nematode resistance. However, measurements of ergot alkaloid and NFL content were not made on roots from plants infested by the nematode. Malinowski et al. (26) noted that there is variability in ergot alkaloid production and the variability may be related to altered root morphology and changes in the rhizosphere of endophyte-infected tall fescue. Through individual screenings, we identified that, at $>50 \mu \mathrm{g} / \mathrm{ml}$, NFL and $\alpha$-ergocryptine are the major alkaloids that act as a $P$. scribneri nematicide. However, when tested as a combination, they are effective nematicides at $50 \mu \mathrm{g} / \mathrm{ml}$. Singly, ergocornine did not affect nematode mortality compared with the other alkaloids. Interestingly, when tested as a potential nematicide in combination with loline and $\alpha$-ergocryptine, our bioassay demonstrated that all three collectively, at $5 \mu \mathrm{g} / \mathrm{ml}$, have negatively affected nematode mortality by $100 \%$.

Our work demonstrates that $N$. coenophialum-infected tall fescue produces nematitoxic compounds (alkaloids and polyphenolics) that are potentiating or synergistic in vitro. Although, individually, some exhibit adverse effects against nematode motility, these allelochemicals working in unison have additive effects that have acute toxicity to $P$. scribneri. Secondary metabolites occur in endophyte-infected tall fescue as variable seasonal mixtures (1). Because the fungal endophyte does not colonize the root, the distribution of toxic compounds tested in this study must be vertically distributed throughout the plant axis, including the root. The translocation of substances in this symbiota might reflect the endophyte presence and the parasitic activity of the nematodes (i.e., an abnormal process). Malinowski et al. (26) presented information that there are chemical changes on the root surface of tall fescue, in response to endophytes, such as altered root membrane morphology and translocation processes reflective of increased releases of phenolics with related reducing activity. Further, ergot alkaloids are also known to alter the polarity of plant cell membranes, creating an altered translocation flow. In addition to this altered directional change in translocation, nematode feeding behavior is expected to increase the downward flow of metabolites to the roots, the sink, where an increased accumulation at feeding sites occurs. This suggests that the roots of nematode-infected tall fescue could have higher levels of ergot alkaloids and other compounds than found in roots of nonnematode-parasitized endophyte-infected plants.

Possible mechanisms of anti-nematode effects exhibited by polyphenols include toxicity, anti-feeding properties, egg hatch inhibition, motility inhibition, blocking the ability to recognize potential host plants, and repulsion in the presence of a susceptible host (42). The mechanism of action for ergot alkaloid to interfere with cellular specific receptors sites, such as neurotransmitters, has been demonstrated (21) for the major tall fescue ergot alkaloid, ergovaline, as well as other ergot alkaloids (13,
16,36). The neurotransmitters dopamine, serotonin, and acetylcholine have been detected in most nematodes, where they play a significant role in nematode behavior, and inhibitors of these neurotransmitters produce numerous effects, including paralysis, inhibition of egg laying and defecation, and death $(16,36,39)$.

The ecological benefits of the secondary metabolites tested here are uncertain but they should assist in extending the role of grass endophytes while offering some probable mechanisms of action against plant-parasitic nematodes. These mechanisms are suggested from the chemical evidence provided and from the structure-activity associations detailed here and in references cited. The results from this study indicate that, although ergot and loline alkaloids are toxic to this species of nematode, there are possible potentiating and synergistic effects expressed at the in planta situation. The larger questions of ecological benefits derived from the association are complex and probably will remain complex. The complexity is confounded by the intended use of symbiotic grasses, which are varied mixtures of ecotypes, some of which may relate to the data examined and discussed here. These natural symbiota have all the merits of allelopathic agents, complete with additional benefits, although some are problematic, especially to grazing livestock. The unknown fractions, polyphenolic and alkaloid compounds tested in this study, should be screened further for their efficacy as nematicides against other nematodes with differing feeding styles to truly assess the spectrum of activity. Of practical and ecological concerns are the effects on the beneficial free-living nematodes and nematiphagus fungi in soils, and not only soils planted with symbiotic tall fescue but also soil exposed to surface water runoff from fescue plantings. Further studies of these associations, details of their bioactive chemicals, and targets of action will clarify their overall ecological role and any importance to and among other forage and range grass situations.

\section{ACKNOWLEDGMENTS}

We thank D. M. Hinton, USDA-ARS, for technical advice; C. Schardl, University Kentucky, USDA-ARS Specific Cooperative Agreement Grant 200506271031 and Department of Plant Pathology, University of Kentucky for his assistance and donation of loline; S. Meyer, P. Crowley, and C. Masler, USDA-ARS, Beltsville, MD, for their technical expertise concerning nematode bioassay and the sterile nematode culture used in this work; H. F. Harrison, U.S. Vegetable Laboratory, USDA, ARS, Charleston, NC, for supplying an authentic sample of 3,5-DICQA; T. Mitchell, USDA-ARS, for his assistance with chemical analyses; and D. Woods, University of Georgia, for his work and assistance with the tall fescue cv. Jesup.

\section{LITERATURE CITED}

1. Agee, C. S., and Hill, N. S. 1994. Ergovaline variability in Acremoniuminfected tall fescue due to environment and plant genotype. Crop Sci. 34:221-226.

2. Bacon, C. W., Porter, J. K., Robbins, J. D., and Luttrell, E. S. 1977. Epichloe typhina from toxic tall fescue grasses. Appl. Environ. Microbiol. 34:576-581.

3. Bacon, C. W., and White, J. F., Jr. 1994. Stains, media, and procedures for analyzing endophytes. Pages 47-56 in: Biotechnology of Endophytic Fungi of Grasses. C. W. Bacon and J. F. White, Jr., eds. CRC Press, Boca Raton, FL.

4. Baldridge, G. D., O’Neill, N. R., and Samac, D. A. 1998. Alfalfa (Medicago sativa L.) resistance to the root-lesion nematode, Pratylenchus penetrans: Defense-response gene mRNA and isoflavonoid phytoalexin levels in roots. Plant Mol. Biol. 38:999-1010.

5. Bernard, E. C., Gwinn, K. D., and Griffin, G. D. 1998. Forage grasses. Pages 427-454 in: Plant and Nematode Interactions. K. R. Barker, G. A. Pederson, and G. L. Windham, eds. American Society of Agronomy, Crop Science Society of America, Soil Science Society of America, Madison, WI.

6. Bush, L. P., Fannin, F. F., Siegel, M. R., Dahlman, D. L., and Burton, H. R. 1993. Chemistry, occurrence and biological effects of saturated pyrrolizidine alkaloids associated with endophyte-grass interactions. Agric. Ecosyst. Environ. 44:81-102. 
7. Ciancio, A. 1995. Observation on the nematicidal properties of some mycotoxins. Fundam. Appl. Nematol. 18:451-454.

8. Clay, K. 1988. Fungal endophytes of grasses: A defensive mutualism between plants and fungi. Ecology 69:10-16.

9. Creek, R., and Wade, G L. 1985. Excretion of phenolic compounds from the roots of Festuca arundinacea, Eragrostis carvula, and Lespedeza striata. Trans. Ky. Acad. Sci. 46:51-55.

10. Giebel, J. 1970. Phenolic content in roots of some Solanaceae and its influence on IAA-oxidase activity as an indicator of resistance to Heterodera rostochiensis. Nematologica 16:22-32.

11. Gwinn, K. D., and Bernard, E. C. 1993. Interactions of endophyteinfected grasses with the nematodes Meloidogyne marylandi and Pratylenchus scribneri. Pages 156-160 in: Proc. 2nd Int. Symp. Acremonium/grass Interactions. D. E. Hume and G. C. M. Latch, eds. AgResearch, Palmerston North, New Zealand

12. Halisky, P. M., and Myers, R. F. 1989. Effect of Acremonium endophytes on parasitic nematodes in Festuca and Lolium grown under turf maintenance. Pages 124-131 in: Rutgers Turfgrass Proc. Rutgers University, New Brunswick, NJ.

13. Hallam, S., E. Singer, E., Waring, D., and Yin, Y. S. 2000. The C. elegans Neuro D homolog cnd-1 functions in multiple aspects of motor neuron fate specification. Development 127:4239-4252.

14. Harrison, H. F., Mitchell, T. R., Peterson, J. K., Wechter, W. P., Majetich, G. F., and Snook, M. E. 2008. Contents of caffeoylquinic acid compounds in the storage roots of sixteen sweet potato genotypes and their potential biological activity. J. Am. Soc. Hortic. Sci. 133:492-500.

15. Hinton, D. M., and Bacon, C. W. 1985. The distribution and ultrastructure of the endophyte of toxic tall fescue. Can. J. Bot. 63:36-42.

16. Horvitz, H. R., Chalfie, M., Trent, C., Sulston, J. E., and Evans, P. D. 1982. Serotonin and octopamine in the nematode Caenorhabditis elegans. Science 216:1012-1014.

17. Hoveland, C. S., Rodriguez-Kabana, R., and Berry, C. D. 1975. Phalaris and tall fescue forage production as affected by nematodes in the field. Agron. J. 67:714-717.

18. Jenkins, W. R. 1964. A rapid centrifugational flotation technique for separating nematodes from soil. Plant Dis. Rep. 48:692.

19. Kimmons, C. A., Gwinn, K. D., and Bernard, E. C. 1990. Nematode reproduction on endophyte-infected and endophyte-free tall fescue. Plant Dis. 74:757-761.

20. Koshino, H. Terada, S., Yoshihara, T., Sakamura, S., Sata, T., and Tajimi, A. 1988. Three phenolic acid derivatives from stromata of Epichloe typhina on Phelum pretense. Phytochemistry 27:1333-1338.

21. Larson, B. T., Harmon, D. L., Piper, E. L., Griffis, L. M., and Bush, L. P. 1999. Alkaloid binding and activation of D2 dopamine receptors in cell culture. J. Anim. Sci. 77:942-947.

22. Loof, P. A. A. 1991. The family Pratylenchidae Thorne, 1949. Pages 363422 in: Manual of Agricultural Nematology. W. R. Nickle, ed. Marcel Dekker, Inc, New York.

23. Lyons, P. C. Plattner, R. D., and Bacon, C. W. 1986. Occurrence of peptide and clavine ergot alkaloids in tall fescue. Science 232:487-489.

24. MacKeen, M. M., Ali, A. M., Abdullah, M. A., Nasir, R. M., Mat, N. B., Razak, A. R., and Kawazu, K. 1997. Antinematodal activity of some Malaysian plant extracts against the pine wood nematode, Bursaphelenchus xylophilus. Pestic. Sci. 51:165-170.

25. Mahajan, R., Singh, P., and Bajaj, K. L. 1985. Nematocidal activity of some phenolic compounds against Meloidogyne incognita. Rev. Nematol. 8:161-164.

26. Malinowski, D. P., Alloush, G. A., and Belesky, D. P. 1998. Evidence for chemical changes on the root surface of tall fescue in response to infection with the fungal endophyte Neotyphodium coenophialum. Plant Soil 205:1-12

27. McGlohon, N. E., Sasser, J. N., and Sherwood, R. T. 1961. Investigations of plant-parasitic nematodes associated with forage crops in North Carolina. N. C. Agric. Exp. Stn. Tech. Bull. 148:1-39.

28. McKennhen, J. D., Bush, R. H., and Fulcher, R. G. 1999. Evaluation of wheat (Triticum aestivum L.) phenolic acids during grain development and their contribution to Fusarium resistance. J. Agric. Food Chem. 47:1476-1482

29. Meyer, S. L. F., Huettel, R. N., and Sayre, R. M. 1990. Isolation of fungi from Heterodera glycines and in vitro bioassays for their antagonism to eggs. J. Nematol. 22:532-537.

30. Nitao, J. K. Meyer, S. L. F., and Chitwood, D. J. 1999. In vitro assays of Meloidogyne incognita and Heterodera glycines for detection of nematode-antagonistic fungal compounds. J. Nematol. 31:172-183.

31. Panaccione, D. G., Kotcon, J. B., Schardl, C. L., Johnson, R D., and Morton, J. B. 2006. Ergot alkaloids are not essential for endophytic fungus-associated population suppression of the lesion nematode, Pratylenchus scribneri, on perennial ryegrass. Nematology 8:583-590.

32. Pedersen, J. F., and Rodriguez-Kabana, R. 1984. Differences among nematode populations in tall fescue pastures in north, central, and south Alabama. Crop Sci. 24:819-821.

33. Pedersen, J. F., Rodriguez-Kabana, R., and Shelby, R. A. 1988. Ryegrass cultivars and endophyte in tall fescue affect nematodes in grass and succeeding Soybean. Agron. J. 80:811-814.

34. Plowright, R. A., Grayer, R. J., Gill, J. R., Rahman, M. L., and Harborne, J. B. 1996. The induction of phenolic compounds in rice after infection by the stem nematode Ditylenchus angustus. Nematologica 42:564-578.

35. Rebois, R. V., and Huettel, R. N. 1986. Population dynamics, roo penetration, and feeding behavior of Pratylenchus agilis in monoxenic root cultures of corn, tomato, and soybean. J. Nematol. 18:392-397.

36. Schafer, W. R., and Kenyon, C. 1995. A calcium-channel homologue required for adaptation to dopamine and serotonin in Caenorhabditis elegans. Nature 375:73-78.

37. Siegel, M. R., and Bush, L. P. 1996. Defensive chemicals in grass-fungal endophyte associations. Pages 81-119 in: Phytochemical Diversity and Redundancy in Ecological Interactions. J. T. Romeo, J. A. Saunders, and P. Barbosa, eds. Plenum Press, New York.

38. Timper, P., Gates, R. N., and Bouton, J. H. 2005. Response of Pratylenchus spp. in tall fescue infected with different strains of the fungal endophyte Neotyphodium coenophialum. Nematology 7:105-110.

39. Weinshenker, D. Z., G. Garriga, and J. H. Thomas. 1995. Genetic and pharmalogical analysis of neurotransmitters controlling egg laying in $C$. elegans. Neuroscience 15:6975-6985.

40. West, C. P., Izekor, E., Oosterhuis, D. M., and Robbins, R. T. 1988. The effect of Acremonium coenophialum on the growth and nematode infestation of tall fescue. Plant Soil 112:3-6

41. Wu, H. W., Haig, T., Pratley, J., Lemerle, D., and An, M. 2001. Allelochemicals in wheat (Triticum aestivum L.): Cultivar differences in the exudation of phenolic acids. J. Agric. Food Chem. 49:3742-3745.

42. Wuyts, N., Swennen, R., and De Waele, D. 2006. Effects of plant phenylpropanoid pathway products and selected terpenoids and alkaloids on the behavior of the plant-parasitic nematodes Radopholus similis, Pratylenchus penetrans, and Meloidogyne incognita. Nematology 8:89101.

43. Zinov'eva, S. V., Udalova, Z. V., I. S. Vasil'eva, I. S., Vanyushkin, S. A., and Paseshnichenko, V. A. 2001. Role of isoprenoid compounds in plant adaptation to biogenic stress caused by parasitic nematodes. Prikl. Biokhim. Mikrobiol. 37:533-541. 